Geological Magazine

www.cambridge.org/geo

\section{Original Article}

Cite this article: Bhowmick S and Mondal TK (2023) Influence of fluid pressure changes on the reactivation potential of pre-existing fractures: a case study in the Archaean metavolcanics of the Chitradurga region, India. Geological Magazine 159: 2346-2360. https:// doi.org/10.1017/S0016756821000881

Received: 30 April 2021

Revised: 29 July 2021

Accepted: 30 July 2021

First published online: 18 October 2021

Keywords:

fractures; fluid pressure; slip tendency; dilation tendency; opening angle

Author for correspondence:

Tridib Kumar Mondal,

Email: tridibkumarmondal@isical.ac.in

\title{
Influence of fluid pressure changes on the reactivation potential of pre-existing fractures: a case study in the Archaean metavolcanics of the Chitradurga region, India
}

\section{Sreyashi Bhowmick ${ }^{1}$ and Tridib Kumar Mondal ${ }^{2}$ (C)}

${ }^{1}$ Department of Geological Sciences, Jadavpur University, Kolkata-700032, West Bengal, India and ${ }^{2}$ Geological Studies Unit, Indian Statistical Institute, 203 B. T. Road, Kolkata-700108, West Bengal, India

\begin{abstract}
The metavolcanics of Chitradurga region host numerous shallow crustal veins and fractures and faults of multiple orientations. Several high and low $P_{\mathrm{f}}$ cycles have been recorded in the region, leading to the reactivation of most of the pre-existing fractures for high $P_{\mathrm{f}}$ and selective reactivation of some well-oriented fractures under low $P_{\mathrm{f}}$ conditions. The pre-existing anisotropy (magnetic fabric) in the metavolcanics acted as the most prominent planar fabric for fracture propagation and vein emplacement under both conditions, thereby attaining maximum vein thickness. In this study, we emphasize the reactivation propensity of these pre-existing fracture planes under conditions of fluid pressure variation, related to the high and low $P_{\mathrm{f}}$ cycles. Multiple cycles of fluid-induced fracture reactivation make it difficult to quantify the maximum/minimum fluid pressure magnitudes. However, in this study we use the most appropriate fluid pressure magnitudes mathematically feasible for a shallow crustal depth of $\sim 2.4 \mathrm{~km}$. We determine the changes in the reactivation potential with states of stress for the respective fracture orientations under both high and low $P_{\mathrm{f}}$ conditions. Dependence of fluid pressure variation on the opening angle of the fractures is also monitored. Finally, we comment on the failure mode and deformation behaviour of the fractures within the prevailing stress field inducing volumetric changes at the time of deformation. We find that deformation behaviour is directly related to the dip of the fracture planes.
\end{abstract}

(c) The Author(s), 2021. Published by Cambridge University Press. This is an Open Access article, distributed under the terms of the Creative Commons Attribution licence (http:// creativecommons.org/licenses/by/4.0/), which permits unrestricted re-use, distribution and reproduction in any medium, provided the original work is properly cited.

\section{Introduction}

Fault and fracture networks are very common in the upper brittle crust. Fractures occur in a wide range of geodynamic settings (e.g. Hancock \& Engelder, 1989), including extensional systems (e.g. Angelier \& Colletta, 1983; Ramsay \& Huber, 1983), thrust and fold belts (e.g. Hancock, 1985; Tavani et al. 2015), diapiric structures (e.g. Rowan et al. 2020), post-orogenic collapse and stabilization of cratons (Mondal \& Mamtani, 2016; Mondal et al. 2020). Fracture formation often involves reactivation of the pre-existing host rock fabric under a compatible stress field (Donath, 1961; Hoek, 1964; Attewell \& Sandford, 1974; Ikari et al. 2015; Mazzarini et al. 2019; Bhowmick \& Mondal, 2020). Upper crustal fluids are mostly channelized through these fracture systems under variable fluid pressure conditions generating a widespread network of veins (Sibson, 1992, 1996, 2000; Jolly \& Sanderson, 1997; Mondal \& Mamtani, 2013; Mazzarini et al. 2019; Bhowmick \& Mondal, 2020). Faults and fractures are most likely to accommodate repeated slip episodes over a period of time, especially if reactivated by fluids (Curzi et al. 2020). However, whether a fracture will behave as a conduit or a barrier depends on its mode of reactivation (Ferrill et al. 2017a, 2019b, 2020). The external stress field plays a key role in fracture formation/propagation. But within the same stress field the favourably oriented fractures are reactivated multiple times while the misoriented ones remain inactive/closed. The probability of reactivation depends on the orientation of the fracture surface with respect to principal stress direction along with the frictional characteristics of the host rock. Slip is possible when the maximum resolved shear stress overcomes/equals the coefficient of friction (Morris et al. 1996). The vein emplacement mechanism within pre-existing fractures depends on the availability of fluids and $P_{\mathrm{f}}$ magnitudes high enough to generate slip/dilation. Thus, finding out the eminence of slip over dilation or vice versa can be effective for understanding the deformation behaviour in fractures (Ferrill et al. 2020). Quantifying the failure mode in fractures that have been reactivated also helps to estimate the volumetric changes associated with vein emplacements. Slip versus dilation patterns can be functional for inferring the failure mode in fractures within a stress field, at the time of deformation (Ferrill et al. 2017a, 2019b, 2020). Tensional failure and shear failure can be easily identified and thus segregated from field observations. However, hybrid failures are 
comparatively difficult to understand, especially if the failure mode changes along the fracture strike/dip orientation.

The present study involves the analysis of veins with multiple orientations in the metavolcanics of the Chitradurga greenstone belt (CGB) of western Dharwar craton. The fractures and faults of the study area are a product of the tectonic stress field associated with the late-stage deformation in Dharwar craton (Sarma et al. 2011; Mondal \& Mamtani, 2016; Mondal \& Acharyya, 2018). The pre-existing foliation fabric ( NW-SE; $\left.\sim 337 / 69^{\circ} \mathrm{NE}\right)$ in the metabasalts has been exploited by propagating late fractures and faults (Mondal \& Mamtani, 2013; Bhowmick \& Mondal, 2020). The states of stress and $P_{\mathrm{f}}$ conditions that led to the reactivation of these fractures and faults have been evaluated in the previous study (Bhowmick \& Mondal, 2020). However, the reactivation potential of these fractures based on their orientation needs to be inferred. This gives a clear idea of the role played by fracture orientations in channelizing fluids and primarily establishes it as the most important criterion for fracture reactivation within an external stress field. Vein thickness and abundance are found to be maximum, parallel to the pre-existing foliation $(\sim \mathrm{NW}-\mathrm{SE})$ of the metabasalts. However, some fractures remained closed even under high $P_{\mathrm{f}}$ conditions. Slip versus dilation tendency patterns help to quantify the failure modes and volumetric changes along all of these fractures.

\section{Background of the study}

Dharwar craton, an integral part of the Indian subcontinent, is known to preserve the age-old Archaean continental crust $>3.0$ $\mathrm{Ga}$ (Jayananda et al. 2006). The eastern and western blocks of the Dharwar craton (EDC and WDC) amalgamated between 2.75 and $2.51 \mathrm{Ga}$, with their accretion along the Chitradurga shear zone (CSZ; see Fig. 1; e.g. Naqvi \& Rogers, 1987; Chadwick et al. 2003; Jayananda et al. 2006). The metasedimentary sequences of the Chitradurga schist belt (CSB; lying on the eastern part of WDC) record three phases of deformation, D1, D2, D3 (Chadwick et al. 1989; Jayananda et al. 2006; Mondal \& Mamtani, 2014; Mondal, 2018). The D1/D2 coaxial deformation with NE-SW-directed compression generated tight to isoclinal asymmetric folds with NW-SE-striking axial plane (Chakrabarti et al. 2006; Mondal \& Mamtani, 2014). This regional deformation also generated a $\sim \mathrm{NW}-\mathrm{SE}$-oriented magnetic fabric in the metabasalts apparently devoid of mesoscopic foliation (as evident from anisotropy in magnetic susceptibility (AMS) analysis; Bhowmick \& Mondal, 2020). Early D3 deformation (NW-SE-directed compression) superposed the D1/D2 structures, resulting in a domebasin geometry in the metasedimentary sequences (Chakrabarti et al. 2006; Mondal \& Mamtani, 2014). The late D3, WNWESE to E-W compression (see Fig. 1) led to the formation of brittle structures in the metabasalts. D3 deformation, coeval with the sinistral movement along CSZ, led to the reactivation of the preexisting fabric ( NW-SE) in metabasalts. The D3 compression also aided in generating fracture and fault planes with specific orientations $\left(\mathrm{R}, \mathrm{Y}, \mathrm{P}, \mathrm{R}^{\prime}, \mathrm{X}, \mathrm{T}\right)$ and movement sense resembling a Riedel shear system (Hancock, 1985), with CSZ as the primary shear boundary. $\mathrm{R}$ and $\mathrm{P}$ are the low-angle synthetic fractures to the shear boundary; $\mathrm{Y}$ is parallel to the shear boundary. $\mathrm{R}^{\prime}$ and $\mathrm{X}$ are the high-angle antithetic shear fractures, whereas $\mathrm{T}$ forms the tensile fractures parallel to the compression direction. It is also envisaged that shear partitioning along such primary shear components generated multiple orientations of faults and fractures hosting quartz veins of variable thickness (see supplementary sheet-1 in Bhowmick \& Mondal, 2020; Mondal et al. 2020).

The quartz veins show criss-cross patterns and are often displaced by each other, so the sense of movement along the fractures containing them is evident (Fig. 2a, b). Some of these veins have crystals growing perpendicular to the vein wall as an evidence of dilational opening of the fractures (Fig. 2c). Most of the quartz veins are NNW-SSEstriking (Fig. 2d), with multiple median lines indicating a crack-seal mechanism suggesting recurrent cracking events due to cyclic fluid ingression (see fig. $3 \mathrm{~g}$ in Bhowmick \& Mondal, 2020). The NW-SE-trending $\left(\sim 337 / 69^{\circ} \mathrm{NE}\right)$ pre-existing fabric provided an easy pathway for fluid flow and vein emplacement considering vein abundance parallel to this orientation. The maximum width and length of the quartz veins are found to be $\sim 0.3$ m (thickness) and $\sim 130 \mathrm{~m}$ respectively. Some of the thick quartz veins accommodate series of moderately to steeply dipping oblique-slip normal faults with slickenside lineations (Fig. 2e). Fault-slip data (mostly oblique-slip normal faults and a few strike-slip faults) used for palaeostress analysis reveal an overall NNE-SSW-directed extension on account of WNW-ESE compression related to the late D3 deformation (Fig. 1; Bhowmick \& Mondal, 2020). In some instances, angular host metabasalt enclaves (clasts) are enclosed within the thick quartz veins, insinuating the effects of fault-valve action in the region or the occurrence of hydrofractures (Fig. 2f). Vein thicknesses along fractures oriented parallel to the magnetic fabric are found to be maximum (maximum recorded thickness $\sim 0.3 \mathrm{~m}$; see supplementary sheet- 1 in the Supplementary Material available online at https://doi.org/10.1017/S001675 6821000881); most of these veins are extensional shear veins (vein type). The process of fracture formation, reactivation and faulting is related to the late D3 deformation with intermittent cycles of fluid pressure build-up leading to fluid-induced faulting, rupturing and vein emplacement in the region (Bhowmick \& Mondal, 2020).

\section{Methodology}

\section{3.a. States of stress and fluid pressure condition}

The fluid pressure conditions and the states of stress under which the veins formed in the region have already been documented in Bhowmick \& Mondal (2020). We have considered the $P_{\mathrm{f}}$ conditions obtained from the methods proposed by Jolly \& Sanderson (1997), using vein orientation data (Bhowmick \& Mondal, 2020). From the studies of Jolly \& Sanderson (1997) it is evident that girdle distribution of vein pole data indicates $P_{\mathrm{f}}>\sigma_{2}$; this suggests a large number of fracture orientations are susceptible to reactivation. However, clustered distribution of vein pole data indicate $P_{\mathrm{f}}<\sigma_{2}$, which suggests a limited range of fracture orientations can be reactivated. Further, parameters like stress ratio $(\Phi)$, driving pressure ratio $\left(R^{\prime}\right)$ and $P_{\mathrm{f}}$ magnitudes can be calculated depending upon the type of distribution (girdle/cluster), using the following equations as proposed by Jolly \& Sanderson (1997) and Baer et al. (1994).

$$
R^{\prime}=\frac{P_{\mathrm{f}}-\sigma_{3}}{\sigma_{1}-\sigma_{3}}=\frac{1+\cos 2 \theta_{2}}{2}
$$

For $P_{\mathrm{f}}>\sigma_{2}$,

$$
\Phi=\frac{\sigma_{2}-\sigma_{3}}{\sigma_{1}-\sigma_{3}}=1-\frac{1-\cos 2 \theta_{2}}{1-\cos 2 \theta_{3}} .
$$




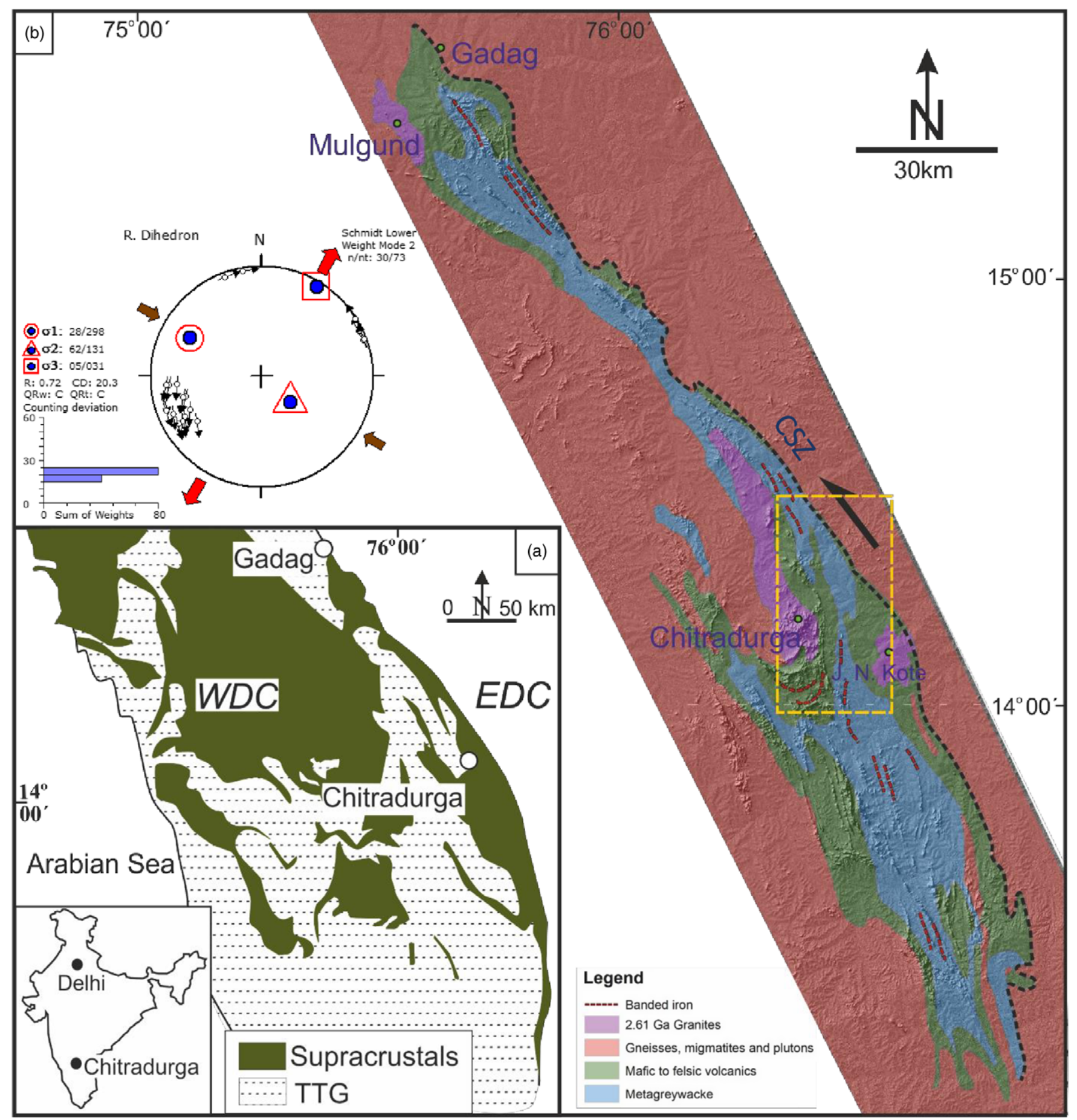

Fig. 1. (a) Regional map of WDC and EDC, South Indian Shield (after Chadwick et al. 2003), within the Indian subcontinent (inset). EDC = eastern Dharwar craton; WDC = western Dharwar craton; TTG = tonalite-trondhjemite-granodiorite; Supracrustals = volcano-sedimentary assemblages. (b) Digital elevation model of the Chitradurga Schist Belt (modified after Jayananda et al. 2013). Eastern boundary of the Chitradurga Schist Belt, representing the Chitradurga Shear Zone (CSZ), marked with dotted black line (in (b)). Yellow box near Chitradurga demarcates the study area. Stress tensor obtained from palaeostress analysis (right dihedron method) using oblique slip normal fault and strike-slip fault data recorded from the metabasalts of the study area. Red arrow marks the extension direction $\left(\sigma_{3}\right)$, and brown arrow marks the principal compression direction. The histogram shows the minimum values for counting deviation. $n$ and $n t$ are the number of data accepted out of the total number of data used for obtaining the best-fit stress tensor respectively. $R$ (stress ratio) $=\left(\sigma_{2}-\sigma_{3}\right) /\left(\sigma_{1}-\sigma_{3}\right)$. Maximum extension is NNE-SSW directed (from Bhowmick \& Mondal, 2020). 

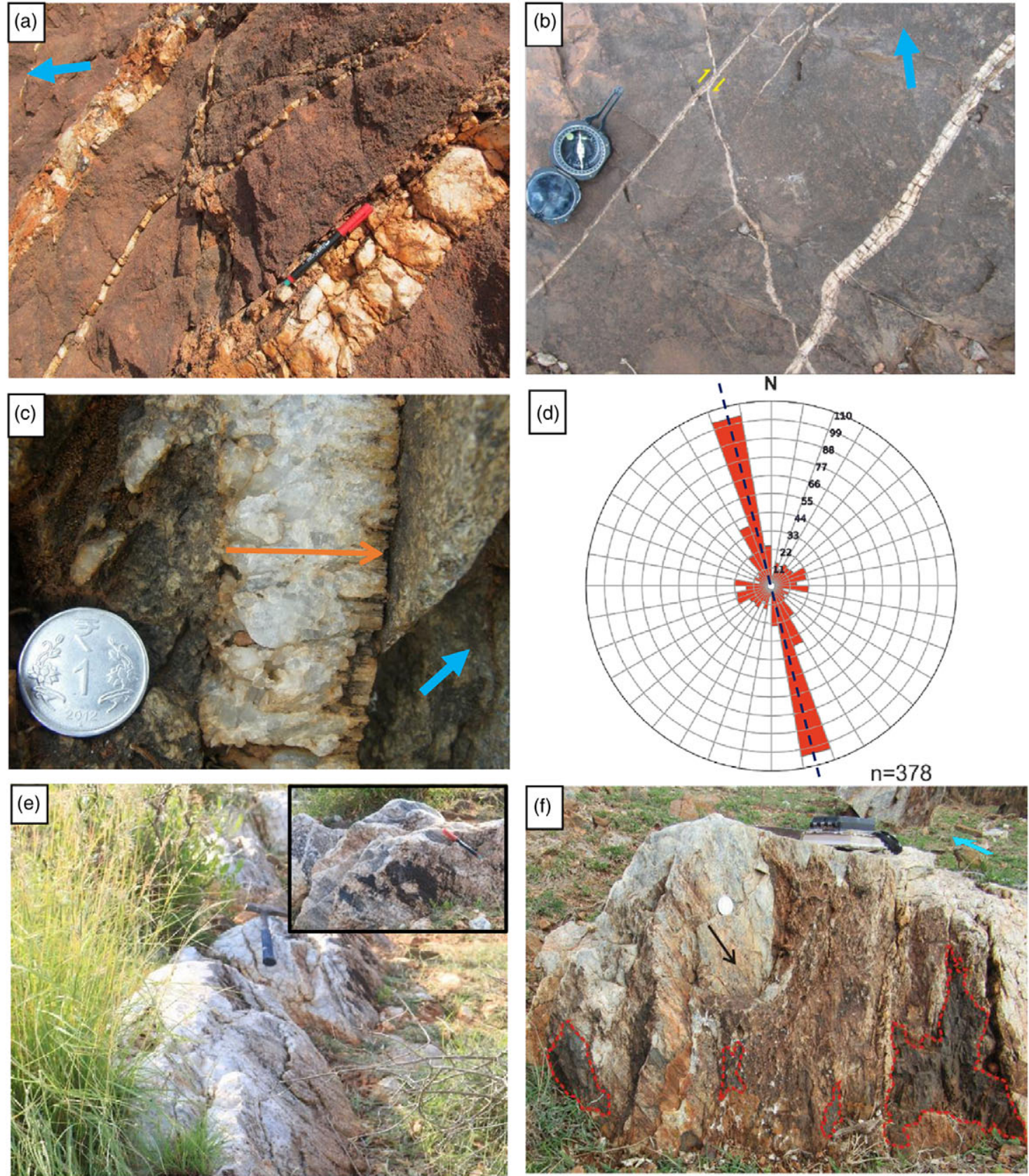

Fig. 2. Field photographs from the study area. (a) Quartz veins in metabasalts having a criss-cross orientation. (b) Cross-cutting nature in quartz veins showing dextral displacement (marked by yellow half-arrows). (c) Close-up view of a quartz vein in metabasalt showing crystal growth direction (orange arrow) perpendicular to the vein wall. (d) Rose diagram showing strike orientation of quartz veins. (e) NE-dipping quartz vein showing slickenside lineations (maximum width recorded $=\sim 0.3 \mathrm{~m}$ ), inset showing close-up of the fault plane found in (e). Marker pen placed along the orientation of the slickenside lineations. (f) Angular chunks of metabasalt (enclaves) enclosed within faulted quartz vein, denoting fault-valve action. Dotted red line demarcates the enclave boundaries. Black arrow marks the slickenside lineations on the fault plane. Blue arrow in the photographs marks the north direction.

For $P_{\mathrm{f}<} \sigma_{2}$,

$$
\Phi=\frac{\sigma_{2}-\sigma_{3}}{\sigma_{1}-\sigma_{3}}=\frac{1+\cos 2 \theta_{2}}{1+\cos 2 \theta_{1}}
$$

The lower-hemisphere equal-area projection of pole to vein data (378 quartz veins; see supplementary sheet-2 in the Supplementary Material available online at https://doi.org/10. 1017/S0016756821000881) in Figure 3a shows a girdle distribution suggesting $P_{\mathrm{f}}>\sigma_{2}$, a high fluid pressure condition. The orientations of the principal stress axes $\left(\sigma_{1}, \sigma_{2}\right.$ and $\left.\sigma_{3}\right)$ are determined from this distribution using Bingham statistics of the Stereonet 9 software. $\sigma_{1}$ (sub-vertical) lies within the empty space devoid of vein pole data. $\sigma_{1} \sigma_{2}, \sigma_{2} \sigma_{3}$ and $\sigma_{1} \sigma_{3}$ planes are constructed, and the ranges of fracture orientations measured with angles $\theta_{2}$ and $\theta_{3}$ along the $\sigma_{1} \sigma_{3}$ and $\sigma_{1} \sigma_{2}$ planes are determined $\left(\theta_{2}=27^{\circ}, \theta_{3}=59^{\circ}\right.$; see Fig. $\left.3 \mathrm{a}\right)$, following Jolly \& Sanderson (1997). Within the girdle distribution of vein pole data, three distinct clusters have been identified based on the relative density maxima of the pole to the vein distribution data. The number of clusters obtained has been assessed through mixed 

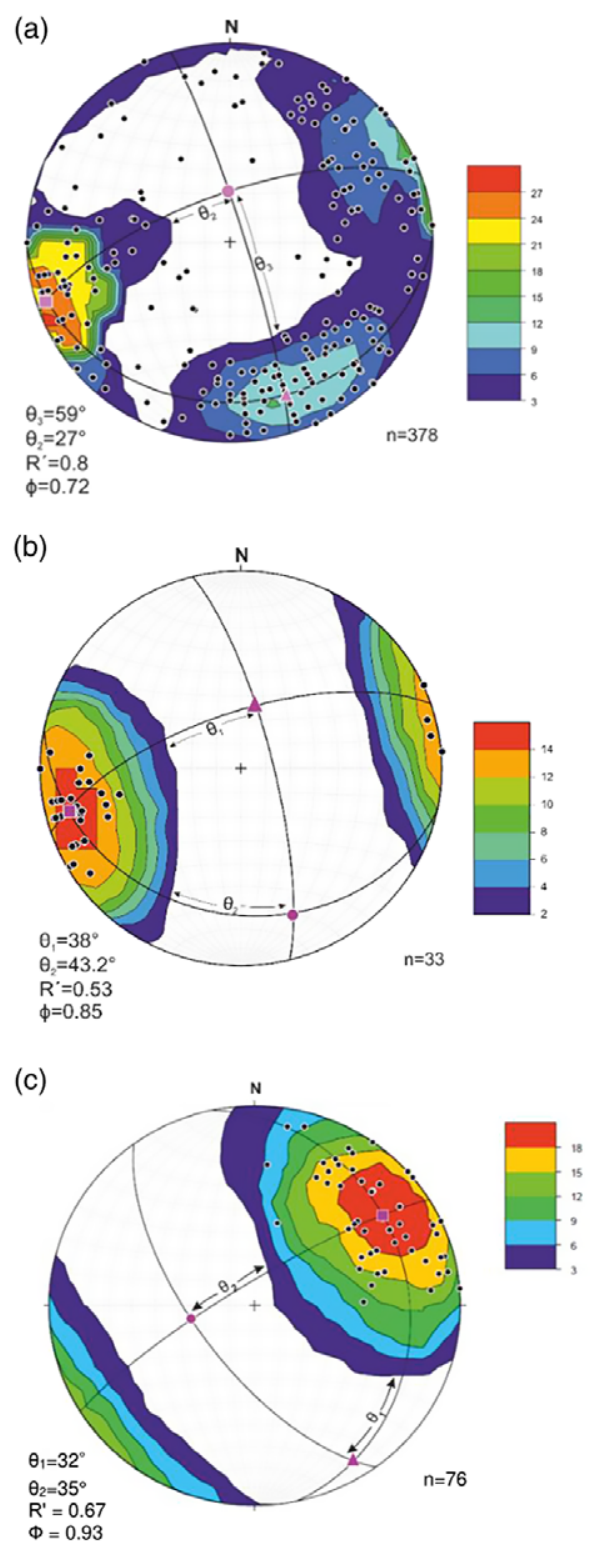

(d)

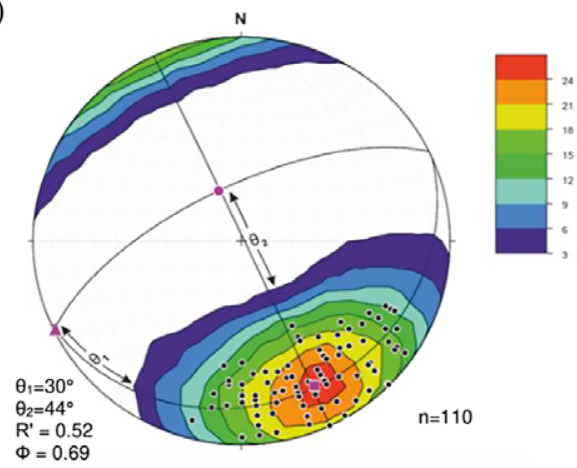

(e)

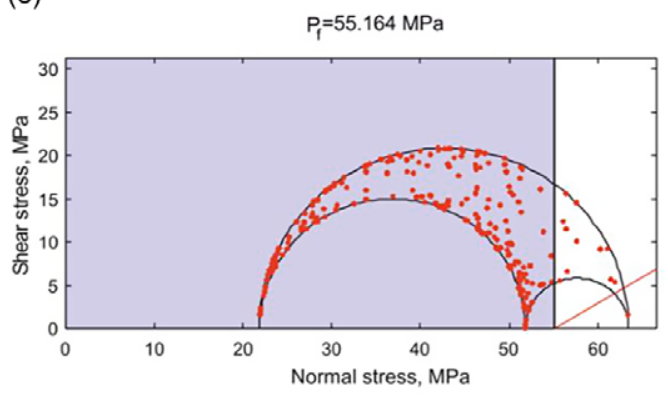

(f)

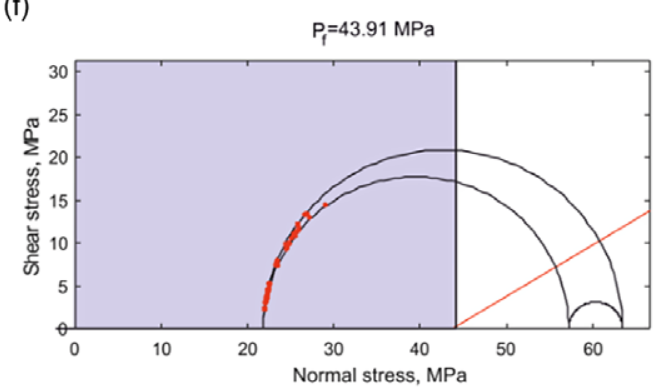

(g)

$P_{f}=49.74 \mathrm{MPa}$

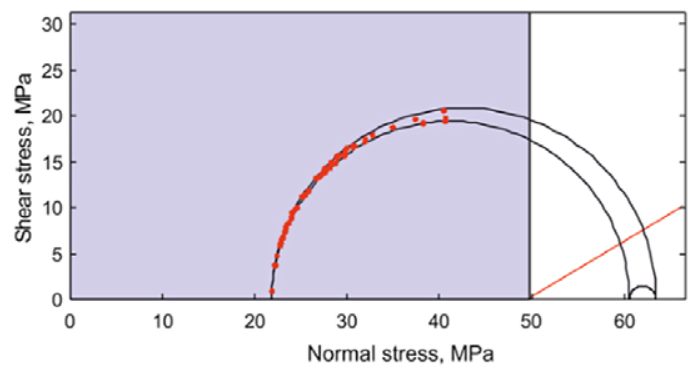

(h)

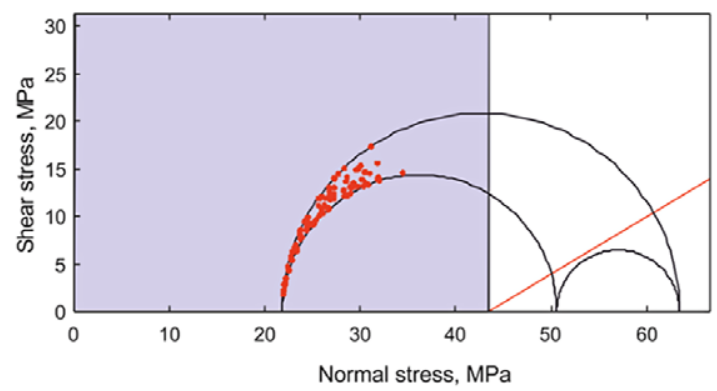

Fig. 3. States of stress and fluid pressure $\left(P_{\mathrm{f}}\right)$ conditions using vein orientation data from the study area (from Bhowmick \& Mondal, 2020). (a-d) Lower-hemisphere equal-area projection of pole to veins. (a) Vein pole data showing girdle distribution, implying $P_{\mathrm{f}}>\sigma_{2}$. (b) Vein pole data forming WSW cluster, $P_{\mathrm{f}}<\sigma_{2}$. (c) Vein pole data forming NE cluster, $P_{\mathrm{f}}<\sigma_{2}$. (d) Vein pole data forming SE cluster, $P_{\mathrm{f}}<\sigma_{2}$ (following Jolly \& Sanderson, 1997). The empty space devoid of vein pole data helps to determine the position of $\sigma_{1}$ (in (a), using Bingham statistics of the Stereonet 9 software); cluster maxima define $\sigma_{3}$ (from (b-d)). Angles $\theta_{1}, \theta_{2}$ and $\theta_{3}$ are measured, and used to determine the stress ratios $(\Phi)$ and driving pressure ratios $\left(R^{\prime}\right)$ respectively. Colour scheme of the legends indicates variation in the contour density. Pink circle $\left(\sigma_{1}\right)$, pink triangle $\left(\sigma_{2}\right)$, pink square $\left(\sigma_{3}\right)$. (e-h) $3 \mathrm{D}$ Mohr circle diagrams: (e) for high $P_{\mathrm{f}}$ condition; (f) for WSW cluster; (g) for NE cluster; (h) for SE cluster. Red dots represent pole-to-vein data; red line represents the reactivation envelope for cohesionless fractures. Vein pole data lying within the blue zone, i.e. to the left of the $P_{\mathrm{f}}$ (black) line, represent fractures susceptible to reactivation (Fractend code available via GitHub (Healy, 2017)). Only a limited range of fractures are susceptible to reactivatation (in $(f-h))$. 
Bingham analysis using $K$ vs $B I C$ (i.e. the number of Bingham components of a mixed Bingham distribution vs Bayesian information criterion; Yamaji \& Sato, 2011). It has been found that the lowest $B I C$ values are obtained for $K=3$ (number of feasible clusters for the given dataset). This justifies the selection of the three data clusters for the analysis. The contour interval and significance level for each of the clusters are selected in order to accommodate the maximum number of data points for obtaining statistically viable data clusters. The WSW cluster (33 vein data, Fig. 3b) is the highestdensity cluster around the $\sigma_{3}$ axis and has been plotted independently. This indicates abundance of NNW-SSE to NW-SE-trending veins with maximum thickness (supplementary sheet-1 in the Supplementary Material available online at https://doi.org/10. $1017 /$ S0016756821000881) oriented parallel to the magnetic fabric of the metabasalt host rocks. A favourably oriented anisotropy lowers the shear strength of the host rock, generating slip at a minimum compressive stress. Moreover, Vishnu et al. (2018) have established a relationship between the magnetic anisotropy and rock strength anisotropy in the metabasalts of CSB. Thus, the pre-existing anisotropy of the metabasalts played a significant role in fracture propagation and vein emplacement (Bhowmick \& Mondal, 2020). The contour interval of the clusters has been extended beyond the data points to incorporate the maximum range of fracture orientations $(\theta)$ lying parallel/sub-parallel to the magnetic anisotropy of the host rock. Along with the WSW cluster (highest-density cluster), the SE cluster (110 vein data) and the NE cluster (with highest data spreading, 76 vein data) are evaluated separately (see supplementary sheet- 2 in the Supplementary Material available online at https://doi.org/10. $1017 /$ S0016756821000881). For each of the clusters, the principal stress axes orientations $\left(\sigma_{1}, \sigma_{2}\right.$ and $\left.\sigma_{3}\right)$ are determined and the $\sigma_{1} \sigma_{2}$ $\sigma_{2} \sigma_{3}$ and $\sigma_{1} \sigma_{3}$ planes are constructed. Ranges of fracture orientations $\theta_{1}$ and $\theta_{2}$ are obtained along the $\sigma_{2} \sigma_{3}$ and $\sigma_{1} \sigma_{3}$ planes respectively, where $\theta_{1}=38^{\circ}, \theta_{2}=43.2^{\circ}$ (WSW cluster, Fig. $3 \mathrm{~b}$ ); $\theta_{1}=32^{\circ}$, $\theta_{2}=35^{\circ}$ (NE cluster, Fig. $3 \mathrm{c}$ ); $\theta_{1}=30^{\circ}, \theta_{2}=44^{\circ}$ (SE cluster, Fig. 3d). The derived parameters $\Phi, R^{\prime}$ and $P_{\mathrm{f}}$ magnitudes for each of the clusters and the girdle distribution of vein pole data are given in Section 4.a.

\section{3.b. Dilation tendency, slip tendency and fracture susceptibility analysis}

Dilation tendency stands for the propensity of a fracture surface to reactivate through dilation under a prevailing stress field. It signifies plane normal opening of a fracture surface, expressed as

$$
T_{d}=\left(\sigma_{1}-\sigma_{n}\right) / \sigma_{D}
$$

where $\left(\sigma_{\mathrm{D}}=\sigma_{1}-\sigma_{3}\right) ; \sigma_{\mathrm{D}}$ is differential stress, $\sigma_{\mathrm{n}}$ is normal stress (Ferrill et al. 1999; Stephens et al. 2017).

Slip tendency is denoted by the ratio of shear stress $\left(\sigma_{\mathrm{s}}\right)$ to normal stress $\left(\sigma_{\mathrm{n}}\right)$, expressed as

$$
T_{\mathrm{s}}=\sigma_{s} / \sigma_{n}
$$

It depends on the state of stress, orientation of a fracture surface within a three-dimensional stress field and the frictional characteristics of the host rock (Morris et al. 1996). Fracture susceptibility $\left(S_{\mathrm{f}}\right)$, is the variation of fluid pressure $\left(\Delta P_{\mathrm{f}}\right)$ within a fracture surface indicating fluid-induced shear reactivation, expressed as

$$
S_{\mathrm{f}}=\sigma_{n}-\left(\sigma_{s} / \mu_{s}\right)
$$

Fracture reactivation depends on the shear and normal stresses acting on the fracture plane, along with the cohesion ( $=0$ in this case) and the static coefficient of friction, $\mu_{s}$ (Mildren et al. 2002; Stephens et al. 2017).

We have calculated the angle $\theta$ between fracture plane normal and the maximum compressive stress, $\sigma_{1}$, using the Stereonet 9 software and numerically quantified the normal and shear stress magnitudes for each fracture plane. Both normal and shear stress magnitudes are dependent on the maximum and minimum principal stresses $\left(\sigma_{1}, \sigma_{3}\right)$ quantified later (see Section 4.a). Fractend code (Healy, 2017) has been used to obtain the lower-hemisphere equal-area projections of vein pole data accentuating slip tendency, dilation tendency and fracture susceptibility variations for all the respective clusters (low $P_{\mathrm{f}}$ conditions) and high $P_{\mathrm{f}}$ conditions (Bhowmick \& Mondal, 2020). Slip and dilation tendency values are numerically determined for each of the fracture orientations. The generated data (see supplementary sheet-2 in the Supplementary Material available online at https://doi.org/10. $1017 /$ S0016756821000881) are used in the later sections to understand the dependence of these parameters on the fracture orientations, states of stress and $P_{\mathrm{f}}$ conditions.

\section{3.c. Determining the opening angle of fractures}

Opening angle $(\mu)$ is calculated by deviation of the dilation vector from the plane normal to the fracture surface. Previously, fieldbased measurements of intrusion attitude and the opening angle were used to constrain tectonic stress axes (Stephens et al. 2018). Normally, for extensional fractures (Mode-I opening) the dilation vector is parallel to the plane-normal $/ \sigma_{3}$ axis. For extensional shear fractures, opening angle is measured in between the plane normal and the offset of the marker beds (giving the dilation vector) along the margin of veins/intrusions. Thus, it can help to distinguish between extensional and extensional-shear fractures directly from field evidence. However, if such offset markers are absent along the intrusion margin it becomes difficult to directly trace the plane-oblique dilation vector. In such cases, the opening angle of fractures can be quantified using the shear stress $(\tau)$, normal stress $\left(\sigma_{\mathrm{n}}\right)$ and $P_{\mathrm{f}}$ acting on the fracture plane at the time of vein emplacement (Delaney et al. 1986; Jolly \& Sanderson, 1997). It is expressed as the ratio between the shear stress and the fluid overpressure/dilation (Delaney et al. 1986).

$$
\mu=\tan ^{-1}\left(\frac{\tau}{P_{\mathrm{f}}-\sigma_{\mathrm{n}}}\right)
$$

When shear to dilation ratio is unity, the opening angle is $45^{\circ}$, a feasible condition for extensional shear reactivation. Once the fluid overpressure exceeds shear stress, the opening angle reduces, ensuring dilational opening of the fractures. However, in the reverse situation, i.e. shear exceeding dilation, fractures tend to slip (shear reactivation). We have numerically quantified the opening angles for all the veins. Ranges of opening angles for the most prominent fracture orientations that were reactivated under the variable fluid pressure conditions help to determine the predominance of slip versus dilation on fracture reactivation. 


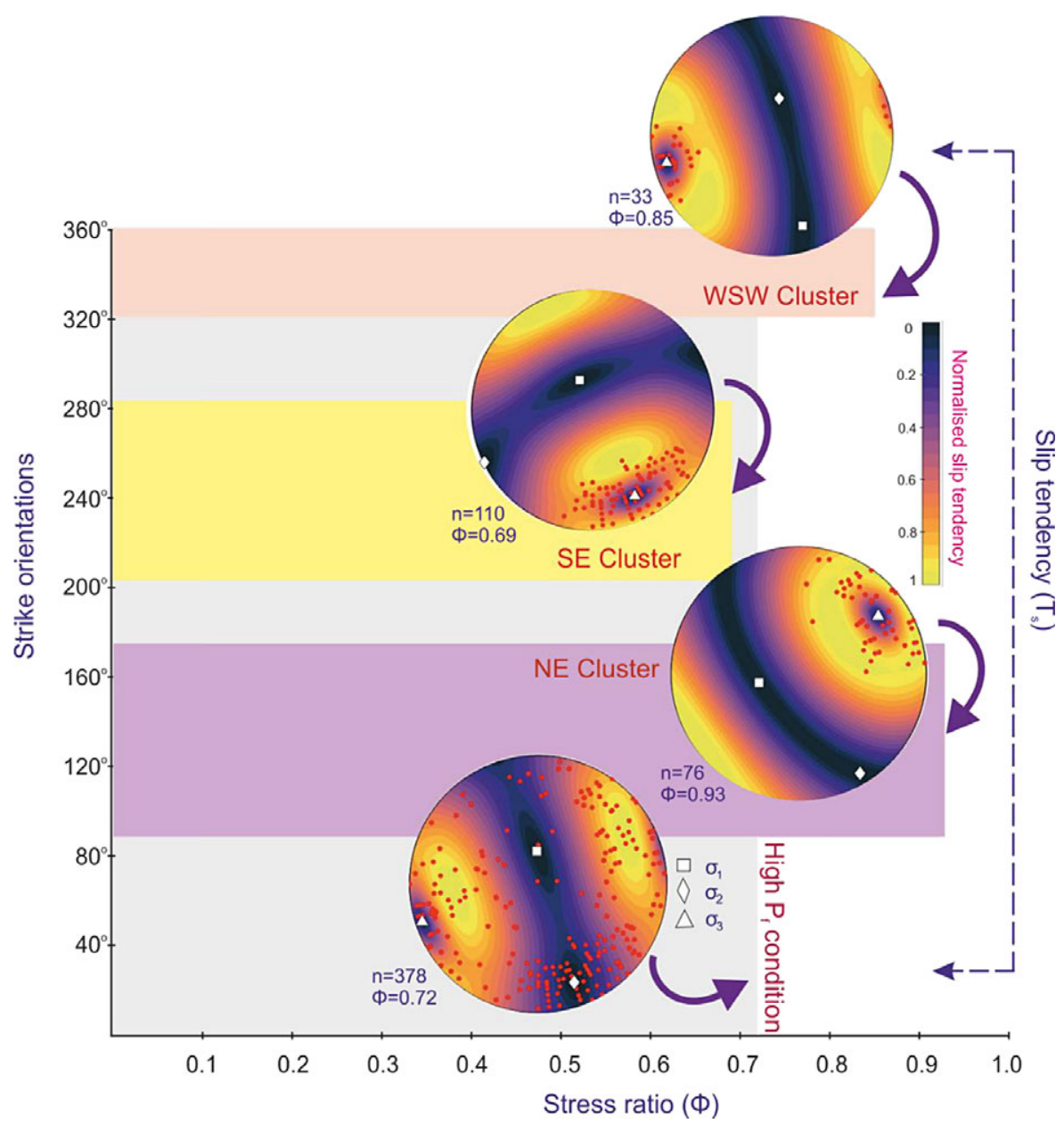

Fig. 4. Slip tendency variation with the states of stress for the respective strike orientation of veins under both high and low $P_{\mathrm{f}}$ conditions. The coloured rectangles represent the ranges of strike orientation and the stress ratio values for each stress state. Lower-hemisphere equal-area projection of vein pole data (red dots) showing slip tendency variation with stress ratio (Fractend code available via GitHub (Healy, 2017)). The warm colour zones represent vein orientations with high slip tendency values (high shear to normal stress). 'Thermal' colour scheme from Thyng et al. (2016). White square $\left(\sigma_{1}\right)$, white diamond $\left(\sigma_{2}\right)$, white triangle $\left(\sigma_{3}\right)$.

\section{Results}

\section{4.a. Fluid pressure determination}

The girdle and cluster distribution of vein pole data from 378 quartz veins (see supplementary sheet- 2 in the Supplementary Material available online at https://doi.org/10.1017/ S0016756821000881) have been used to obtain the high and respective low $P_{\mathrm{f}}$ conditions assisting vein emplacement in the metabasalts (Fig. 3, modified from Bhowmick \& Mondal, 2020). The $P_{\mathrm{f}}$ magnitudes used in this study are instances of high and low $P_{\mathrm{f}}$ conditions indicating cyclic variation of $P_{\mathrm{f}}$ in response to the tectonic stress field and availability of fluid for vein emplacement. The approximated $P_{\mathrm{f}}$ values are close enough and befitting for a shallow crustal vein emplacement $(\sim 2.4 \mathrm{~km})$ process within the prevailing stress field (Bhowmick \& Mondal, 2020). Further, these values help to document the reactivation potential of the pre-existing fractures that mediated fluid flow in the region.

The principal stress magnitudes are evaluated considering the depth of fracturing and faulting to be $2.4 \mathrm{~km}$ according to Bhowmick \& Mondal (2020). In a normal faulting regime, $\sigma_{\mathrm{v}}=\sigma_{1}$, using $\sigma_{1}=h \rho g$, where $h=$ depth of fracturing in metabasalts $(\sim 2.4 \mathrm{~km}), \rho=$ approximate bulk density of crust $\left(2700 \mathrm{~kg} / \mathrm{m}^{3}\right), g=9.8 \mathrm{~m} / \mathrm{s}^{2}, \sigma_{1}=63.5 \mathrm{MPa}$. Similarly, using the empirical approach by McGarr (1980) and Mazzarini et al. (2019), at a crustal depth $<7 \mathrm{~km}$, the differential stress $(\Delta \sigma)=2 \tau_{\mathrm{m}}$, where $\tau_{\mathrm{m}}$ is the maximum shear stress at depth $z$ (in $\mathrm{km}$ ): $\tau_{\mathrm{m}}=5.0+6.6 z$. Therefore, at $\sim 2.4 \mathrm{~km}, \sigma_{3}=21.82$ MPa (Bhowmick \& Mondal, 2020).

For girdle distribution of vein pole data (Fig. 3a), implying high $P_{\mathrm{f}}$ condition $\left(P_{\mathrm{f}}>\sigma_{2}\right), \Phi=0.72, R^{\prime}=0.8, P_{\mathrm{f}}=55.164 \mathrm{MPa}$ (Fig. 3a, e). For the respective clusters, implying low $P_{\mathrm{f}}$ conditions $\left(P_{\mathrm{f}}<\sigma_{2}\right)$, $\Phi=0.85, R^{\prime}=0.53, P_{\mathrm{f}}=43.91 \mathrm{MPa}$ (WSW cluster, Fig. $3 \mathrm{~b}, \mathrm{f}$ ); $\Phi=0.93, R^{\prime}=0.67, P_{\mathrm{f}}=49.74 \mathrm{MPa}$ (NE cluster, Fig. 3c, g); $\Phi=0.69, R^{\prime}=0.52, P_{\mathrm{f}}=43.49 \mathrm{MPa}$ (SE cluster, Fig. $3 \mathrm{~d}, \mathrm{~h}$ ). We have further used these values to analyse the influence of these parameters on the reactivation potential of the veins.

\section{4.b. Dilation tendency, slip tendency and fracture susceptibility}

We have obtained graphs determining dilation tendency, slip tendency and fracture susceptibility variation for vein orientations at different stress ratios $(\Phi)$. Figure 4 shows the range of fracture 


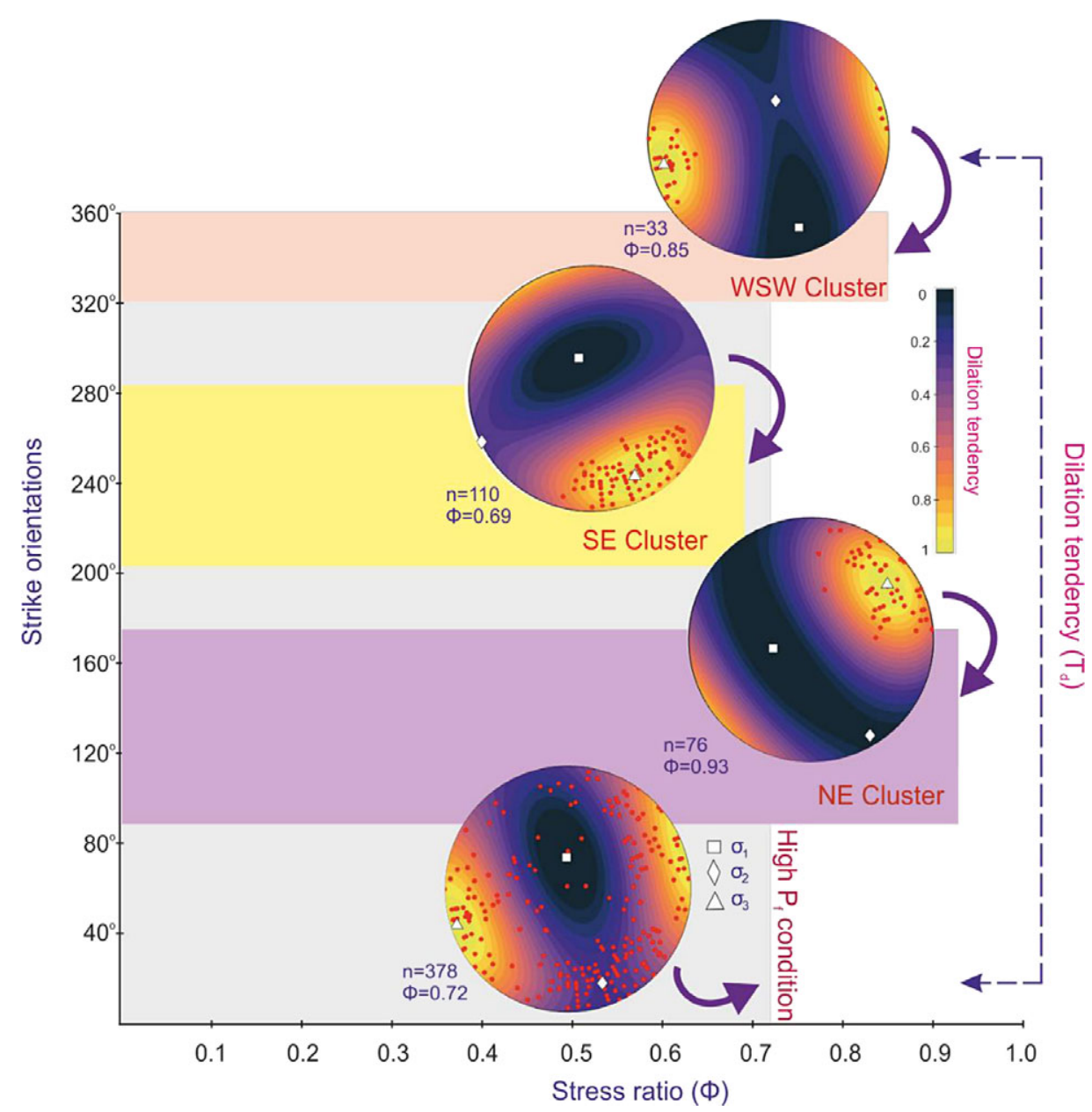

Fig. 5. Dilation tendency variation with the states of stress for the respective strike orientation of veins under both high and low $P_{\mathrm{f}}$ conditions. The coloured rectangles represent the ranges of strike orientation and the stress ratio values for each stress state. Lower-hemisphere equal-area projection of vein pole data (red dots) showing dilation tendency variation with stress ratio (Fractend code available via GitHub (Healy, 2017)). The warm colour zones represent vein orientations with high dilation tendency values (indicating fracture perpendicular opening). 'Thermal' colour scheme from Thyng et al. (2016). White square $\left(\sigma_{1}\right)$, white diamond $\left(\sigma_{2}\right)$, white triangle $\left(\sigma_{3}\right)$.

orientations for the clusters and vein girdle with variation in slip tendency values at different stress ratios $(\Phi)$. Similarly, Figure 5 shows the range of fracture orientations for all clusters and the vein girdle with variation in dilation tendency values at different stress ratios $(\Phi)$. Figure 6 shows the range of fracture orientations for the vein clusters and girdle with variation in fracture susceptibility values at different stress ratios $(\Phi)$. Figure 7 represents the range of vein orientations for the vein clusters and girdle, consistent with the changes in driving pressure ratio $\left(R^{\prime}\right)$. In order to visualize the role of $P_{\mathrm{f}}$ in slip tendency variation for the respective strike orientation of veins under both high and low $P_{\mathrm{f}}$ conditions, strike orientation is plotted against $R^{\prime}$ (see supplementary sheet-3 in the Supplementary Material available online at https://doi.org/10.1017/S0016756821000881).

\section{Discussion}

\section{5.a. Dependence of slip tendency, dilation tendency and fracture susceptibility on the states of stress and fracture orientation}

Field studies show multiple median lines within a single quartz vein as evidence of a crack-seal mechanism, indicating cyclic fluid ingression and fault-valve action in the region. The vein emplacement mechanism within pre-existing discontinuities depends on the regional stress field (far-field), stress ratio and fluid pressure condition; such that the fluid pressure build-up exceeds the stresses acting on the discontinuity wall enabling dilation/slip along the discontinuity planes, a mechanism known as fault-valve action. Subsequently, fluid flows into the discontinuities, a phenomenon analogous to burping, triggering a drop in the fluid pressure leading to the formation of veins. Thus, repeated cycles of elevated and depleted fluid pressure generate cross-cutting veins (Sibson, 1992, 1996; Miller et al., 1994; Mondal \& Mamtani, 2013). Therefore, veins with multiple orientations, forming criss-cross patterns (mesh-like structure) in the field have been attributed to such $P_{\mathrm{f}}$ variations. Usually, a high $P_{\mathrm{f}}$ influx is followed by multiple low $P_{\mathrm{f}}$ cycles that can reactivate a small range of fractures, before the $P_{\mathrm{f}}$ is again sufficiently high to reactivate a wider range of fractures. Therefore, it is envisaged that such cyclic variation in $P_{\mathrm{f}}$ continues until the entire fluid source is exhausted. However, it is very difficult to quantify the exact number of such high and low $P_{\mathrm{f}}$ cycles and the precise $P_{\mathrm{f}}$ magnitude for each cycle from such a vast event. We could only provide a few instances of this $P_{\mathrm{f}}$ variation from our field observations and data distribution pattern. After a high $P_{\mathrm{f}}$ cycle, the pressure suddenly drops and minerals are precipitated, sealing the fractures until the next phase of $P_{\mathrm{f}}$ 


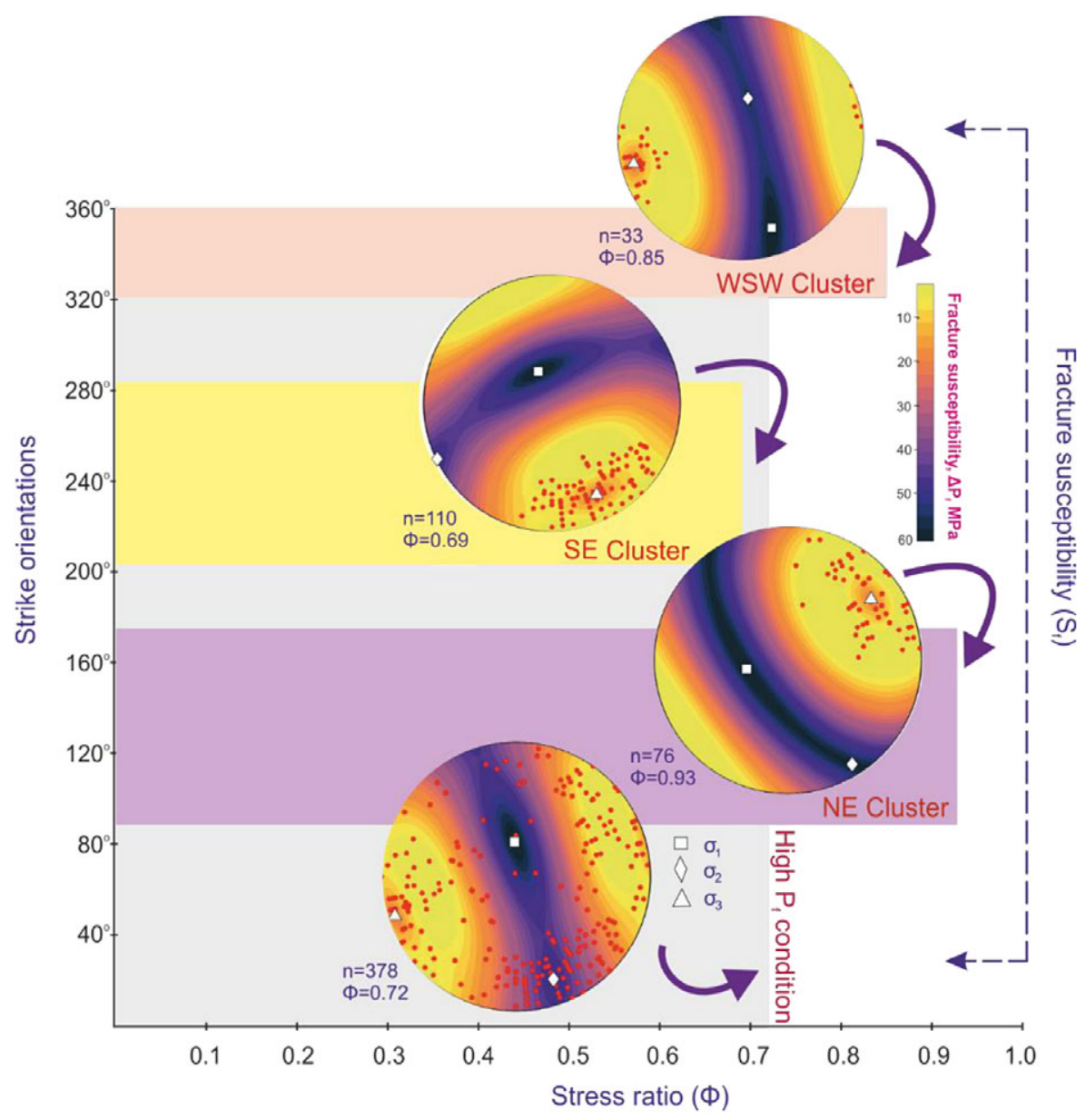

Fig. 6. Fracture susceptibility variation with the states of stress for the respective strike orientation of veins under both high and low $P_{\mathrm{f}}$ conditions. The coloured rectangles represent the ranges of strike orientation and the stress ratio values for each stress state. Lower-hemisphere equal-area projection of vein pole data (red dots) showing variation in fracture susceptibility with stress ratio (Fractend code available via GitHub (Healy, 2017)). The warm colour zones represent vein orientations with low $P_{\mathrm{f}}$ variation, i.e. high reactivation potential / high fluid influx. 'Thermal' colour scheme from Thyng et al. (2016). White square $\left(\sigma_{1}\right)$, white diamond $\left(\sigma_{2}\right)$, white triangle $\left(\sigma_{3}\right)$.

rise. Therefore, two consecutive high $P_{\mathrm{f}}$ cycles cannot take place simultaneously. However, it is more likely that multiple low $P_{\mathrm{f}}$ cycles can follow a high $P_{\mathrm{f}}$ cycle and in that case the girdle and clusters might overlap. Therefore, the respective clusters and the girdle distribution of vein pole data each represent a $P_{\mathrm{f}}$ condition under which a fracture may reactivate. Figure 4 shows the range of fracture orientations for the respective stress ratios along with the lower-hemisphere stereoplots showing slip tendency variation for each stress state. The role of $P_{\mathrm{f}}$ in slip tendency analysis shows that under both high and low $P_{\mathrm{f}}$ conditions the fractures oriented parallel/sub-parallel to the magnetic fabric have high slip tendency (supplementary sheet-3 in the Supplementary Material available online at https://doi.org/10.1017/S0016756821000881). For the WSW and NE clusters (considering the maximum cluster density), the orientations showing maximum slip tendency values are mostly consistent with the pre-existing magnetic fabric of the metabasalts, that were reactivated multiple times under both high and low $P_{\mathrm{f}}$ conditions. However, for the SE cluster (with highest data spreading) the orientations are comparable to the $\mathrm{R}^{\prime}, \mathrm{X}$ and $T$ range of fractures representing the Riedel shear components.

Similarly, Figure 5 gives the range of fracture orientations for the respective stress ratios, along with the lower-hemisphere stereoplots showing dilation tendency variation for each stress state. The warm zones consistent for high dilation tendency values partly overlap the warm zones for high slip tendency values. The fracture orientations lying within this overlapping zone might have suffered high dilation $\geq 0.8$ with moderately high slip tendency $\geq 0.6$.

Figure 6 gives the range of fracture orientations for the respective stress ratios with the lower-hemisphere stereoplots showing fracture susceptibility variation for each stress state. The warm zones indicate less variation in fluid pressure $\left(\Delta P_{\mathrm{f}}\right)$, implying high fluid influx and high chances of fluid-induced fracture reactivation. Thus, vein pole data lying within the warm zone consistent with high dilation and moderately high slip tendency will certainly encounter high fracture susceptibility.

\section{5.b. Fracture orientation vis-à-vis driving pressure ratio}

The wide range of fracture orientations in the metabasalts were selectively reactivated under variable $P_{\mathrm{f}}$ conditions. Driven by the tectonic stresses, the process of fracture formation/propagation continued with intermittent cycles of fluid pressure build-up, leading to fluid-induced faulting and reactivation of the pre-existing fractures (Bhowmick \& Mondal, 2020). Chances of hydrofracturing are prominent even without a lithostatic and supra-lithostatic fluid pressure, when $P_{\mathrm{f}}$ exceeds the normal stress $\left(\sigma_{\mathrm{n}}\right)$ and the tensile strength of the rock. For some fracture orientations, the $P_{\mathrm{f}}$ value was not high enough to overcome the $\sigma_{\mathrm{n}}$ and tensile strength 


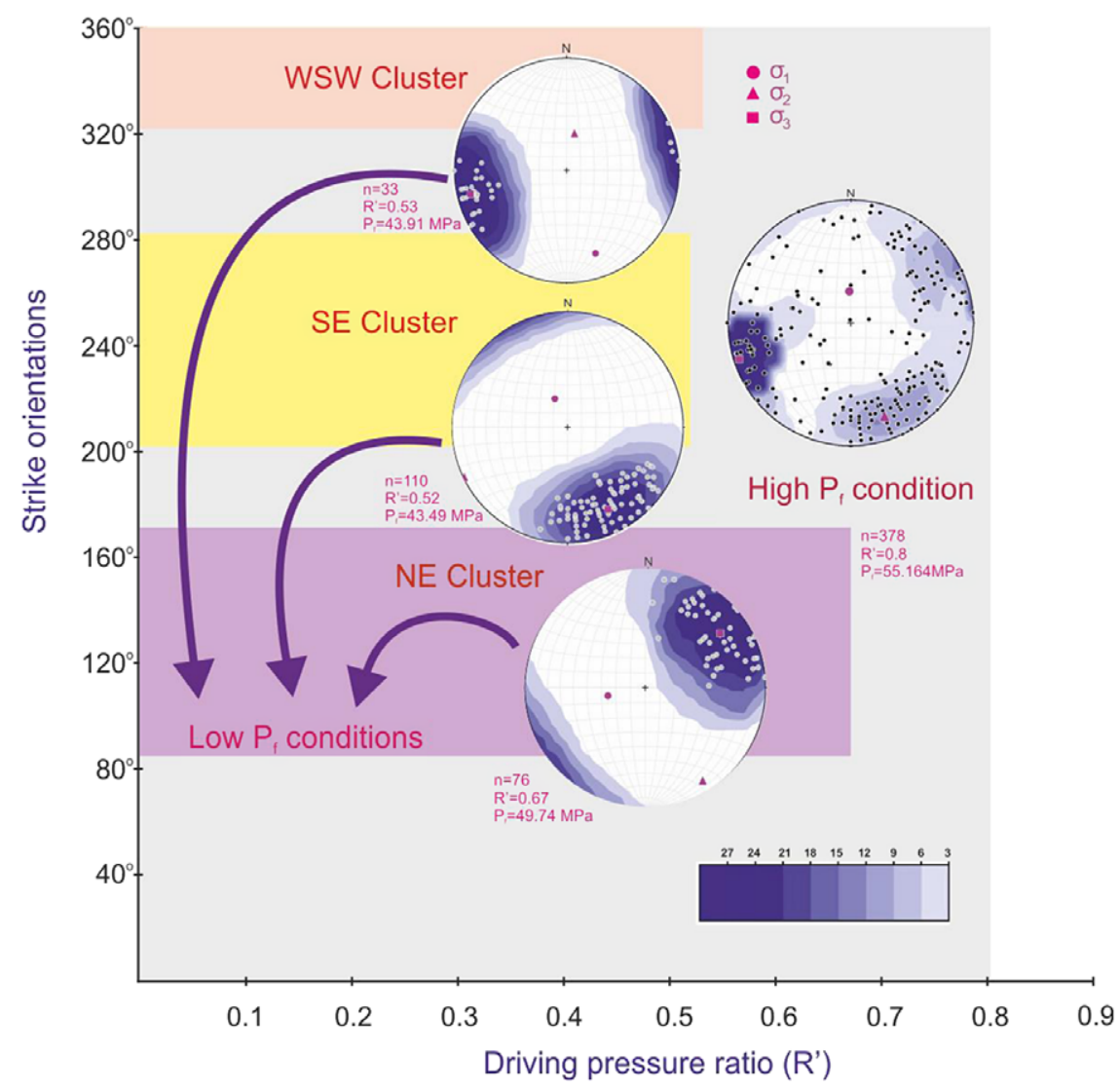

Fig. 7. Variation in driving pressure ratio with strike orientation of veins for both high and low $P_{\mathrm{f}}$ conditions. The coloured rectangles represent the ranges of strike orientation and the driving pressure ratio values for each stress state. Lower-hemisphere equal-area projection of vein pole data (white and grey dots) for each stress state (Stereonet 9 software). Pink circle $\left(\sigma_{1}\right)$, pink triangle $\left(\sigma_{2}\right)$, pink square $\left(\sigma_{3}\right)$.

of the host. However, the instances of $P_{\mathrm{f}}$ conditions inferred can be further used to enunciate the range of fracture orientations that were favourably oriented for reactivation under a particular $P_{\mathrm{f}}$ magnitude. In Figure 7, the range of fracture orientations consistent with the derived driving pressure ratios $\left(R^{\prime}\right)$ and $P_{\mathrm{f}}$ magnitudes are given along with the stereoplots for all the clusters (low $P_{\mathrm{f}}$ ) and girdle distribution (high $P_{\mathrm{f}}$ ) of vein pole data. It is to be noted that at the highest driving pressure ratio $\left(R^{\prime}=0.8\right) /$ highest $P_{\mathrm{f}}$ magnitude $\left(P_{\mathrm{f}} \sim 55.164 \mathrm{MPa}\right)$, graphically all possible orientations are susceptible to reactivation. However, from field observations we have found fractures devoid of vein infillings. Even under high $P_{\mathrm{f}}$ conditions and irrespective of fluid availability such misoriented fractures could not be reactivated under the prevailing stress field. However, lack of connectivity to a fluid source could also be the possible reason for the absence of veins in these fractures.

\section{5.c. Opening angle versus fracture orientation}

The opening angles for fractures vary, depending on the mode of reactivation. For dilational fractures (plane normal opening) the range is narrow, whereas for shear fractures (dilation vector inclined to the plane normal) the range broadens. Figure 8 gives the opening angle range for each of the clusters along with their lower-hemisphere equal-area stereoplots. The 3D Mohr circles also provide the respective fluid pressure lines, beyond which fractures cannot reactivate. The warm colour zones with lower range of opening angles represent dilational opening, while with increasing shear-to-dilation ratio the colour gradually attains a darker shade. The white zone in the stereoplots stands for the closed fractures misoriented for reactivation within the prevailing stress field. However, with increasing $P_{\mathrm{f}}$, gradually the white area reduces to an elliptical space (Fig. 8h).

The numerically derived slip and dilation tendency values along with the opening angles for the vein orientations have been used to obtain the graphs in Figures 9 and 10. The detailed interpretation of these graphs and their implications in this study have been elaborated in this section. Fracture orientations of the study area are a product of the tectonic stress field related to the late D3 deformation, forming a Riedel shear system with CSZ as the shear boundary (Bhowmick \& Mondal, 2020). Some of the prominent fractures ( $R$, $\mathrm{Y}$ and $\mathrm{P})$ propagated parallel to the pre-existing fabric ( NW-SE; $337 / 69^{\circ} \mathrm{NE}$ ) of the metabasalts (WSW and NE clusters). Out of these, the steeply dipping ones are dilational with dilation tendency $\geq 0.8$ and opening angles ranging between $0^{\circ}$ and $20^{\circ}$ (see Fig. 9). However, the moderately dipping fractures with high dilation tendency $\geq 0.8$ and moderately high slip tendency $\geq 0.6$, are consistent with opening angles ranging between $20^{\circ}$ and $70^{\circ}$ (Fig. 9). Other fractures resembling the $\mathrm{R}^{\prime}, \mathrm{X}$ and $\mathrm{T}$ shear components (SE cluster) have opening angles ranging between $0^{\circ}$ and $50^{\circ}$, indicating moderate slip tendency with high dilation tendency (Fig. 9). The fracture orientations with negative opening angles lying within the white elliptical space of the stereoplot (see Fig. 9) are closed fractures; those could have reactivated only under fluid overpressure $\left(P_{\mathrm{f}}>\sigma_{\mathrm{n}}\right)$. These orientations could be related to compactive shear fractures, but such field evidence was not perceived. 
(a)

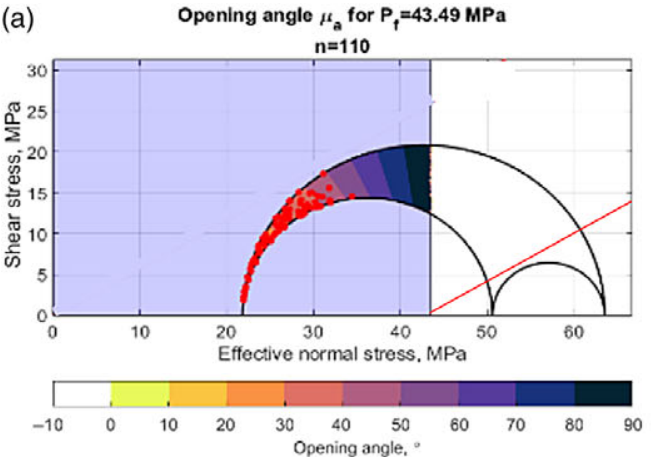

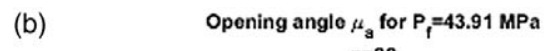

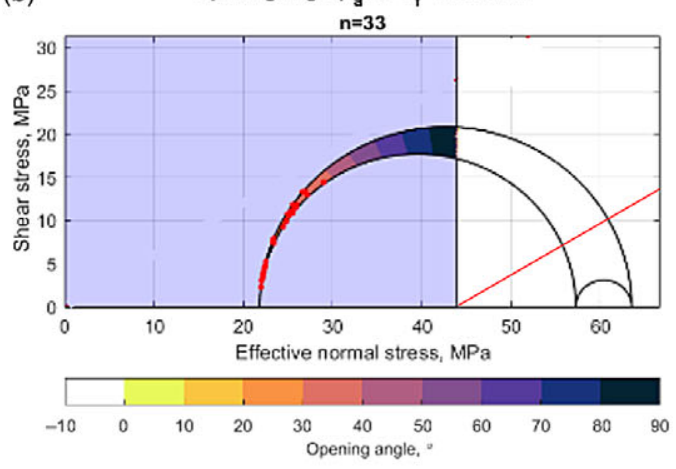

(c)

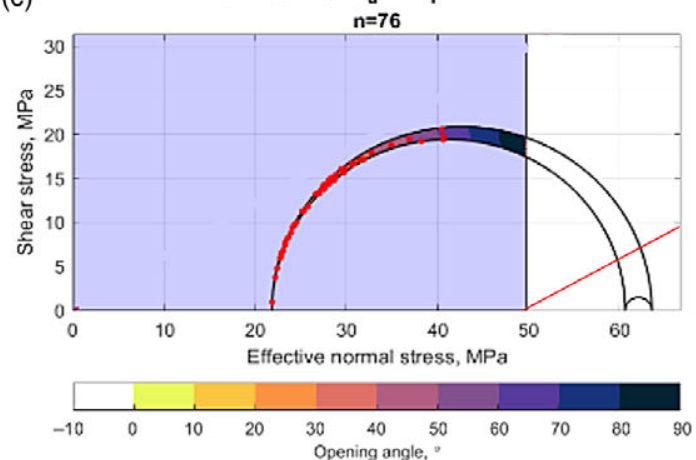

(d)

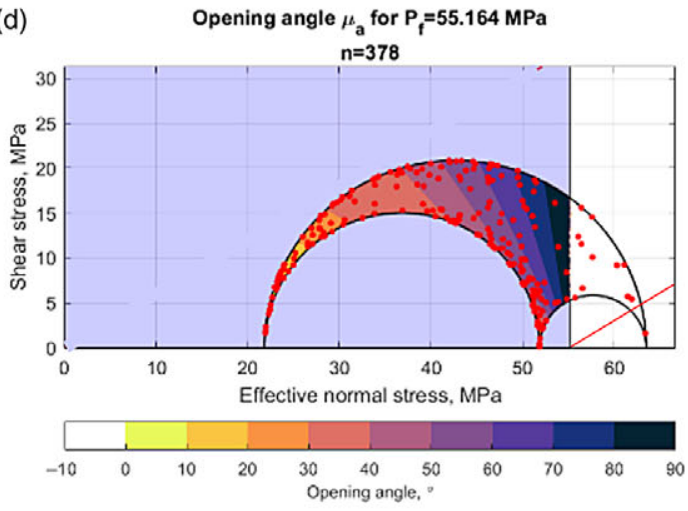

(e)

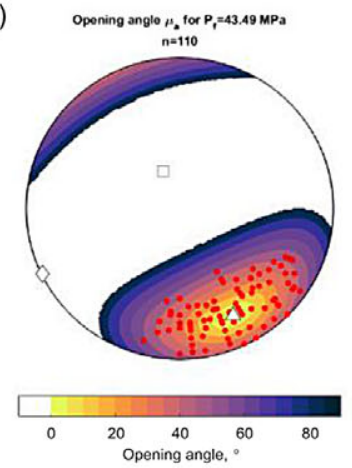

(f) Opening angle $\mu_{a}$ for $P_{f}=43.91 \mathrm{MPa}$

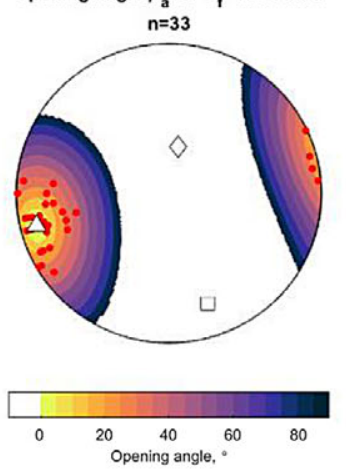

(g) Opening angle $\mu_{a}$ for $P_{f}=49.74 \mathrm{MPa}$

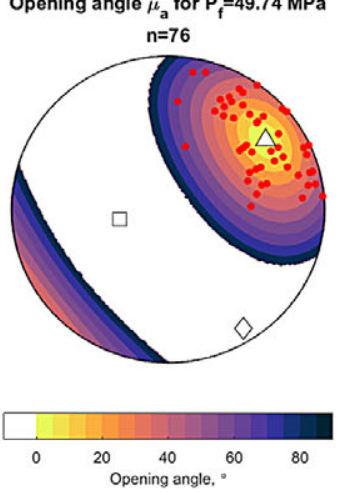

(h)

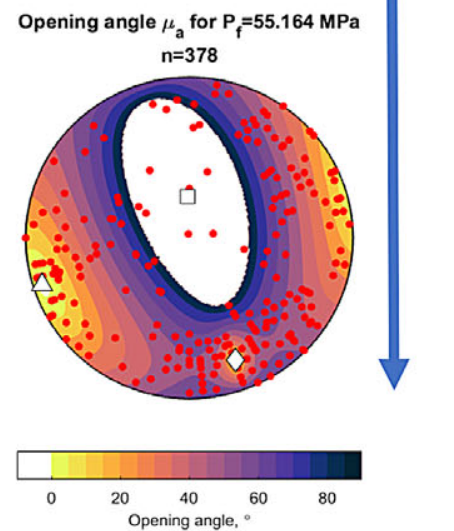

Fig. 8. Opening angle variation in veins for the respective states of stress and increasing $P_{\mathrm{f}}$. (a-d) $3 \mathrm{D}$ Mohr circle diagrams denoting the changes in opening angle with increasing $P_{\mathrm{f}}$ (e-h) Lower-hemisphere equal-area projection of vein pole data denoting the corresponding clusters and the high $P_{\mathrm{f}}$ girdle (Fractend code available via GitHub (Healy, 2017)): (e) SE cluster; (f) WSW cluster; (g) NE cluster; (h) high $P_{\mathrm{f}}$ girdle. (a-c) Even in low $P_{\mathrm{f}}$ conditions, the favourably oriented fractures have a lower range of opening angles, indicating fracture perpendicular opening. (d) In high $P_{\mathrm{f}}$ conditions, all possible vein orientations are reactivated with a broader range of opening angles. (e-h) With increasing $P_{\mathrm{f}}$, the white space for closed/misoriented fractures reduces (unsuitable for reactivation). 'Thermal' colour scheme from Thyng et al. (2016). 


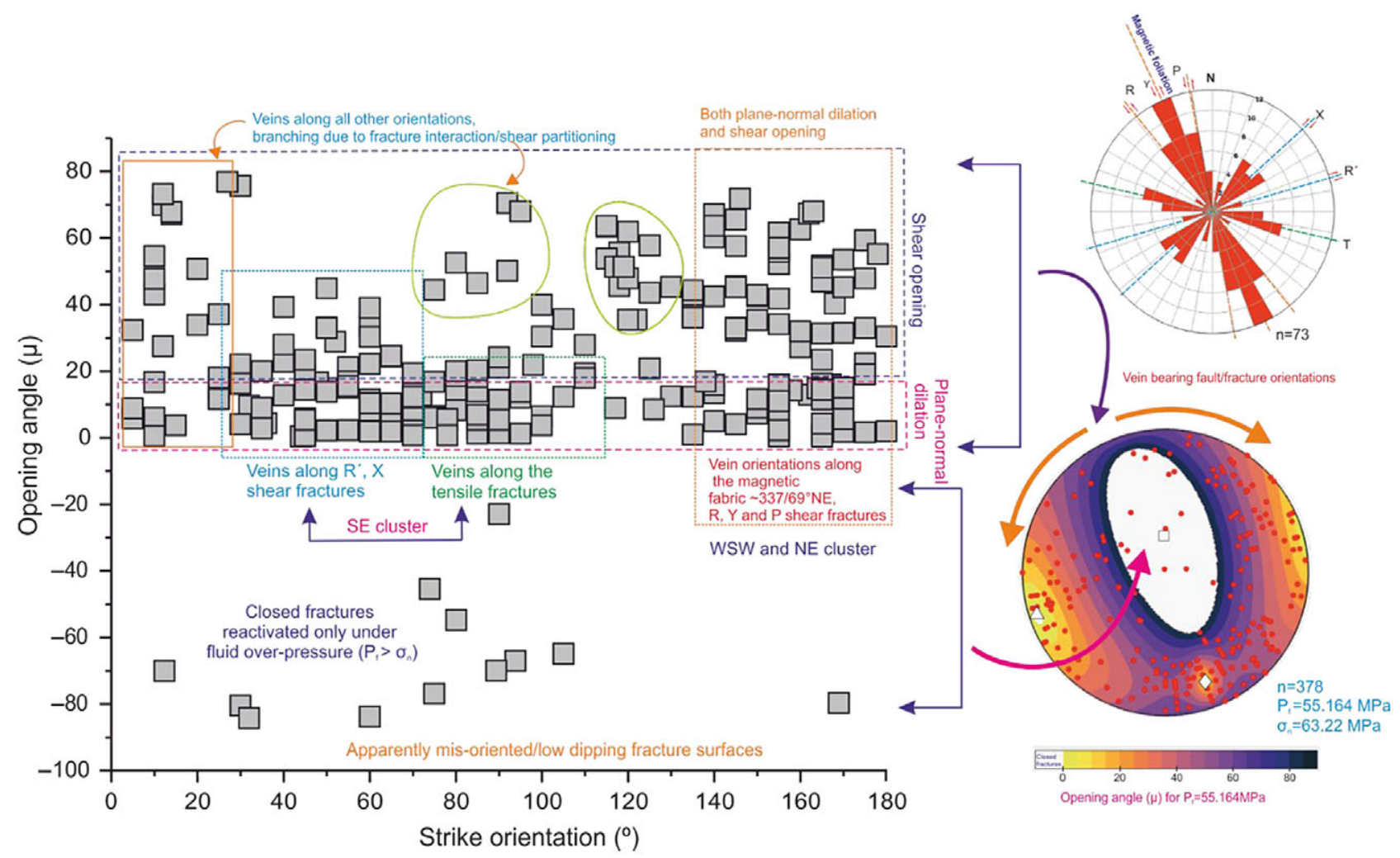

Fig. 9. Opening angle as a function of fracture orientation. Major fracture/fault orientations (given in rose diagram) and their respective range of opening angles (graphically represented). Lower-hemisphere equal-area projection showing the range of opening angles for the veins and closed fractures respectively (Fractend code available via GitHub (Healy, 2017)). 'Thermal' colour scheme from Thyng et al. (2016). Misoriented fractures (closed fractures) are observed even at the highest determined $P_{\mathrm{f}}$.

\section{5.d. Mode of failure: slip tendency versus dilation tendency}

The numerically obtained slip versus dilation tendency data plotted in Figure 10 match the expected trend as discussed in Ferrill et al. (2019a). The pattern shows the reactivation modes and volumetric changes along the prominent fracture orientations. We have found that most of the steeply dipping fractures (Fig. 11) underwent tensional failure (Fig. 10) with opening angles ranging between $0^{\circ}$ and $20^{\circ}$ (also see Fig. 9), while the moderately dipping ones (Fig. 11) suffered shear failure (Fig. 10), with opening angles ranging between $20^{\circ}$ and $80^{\circ}$ (also Fig. 9). In between both, there is a transitional range of hybrid fractures (Fig. 10) consistent with both moderately high slip and dilation tendency, with opening angles ranging between $30^{\circ}$ and $50^{\circ}$. Considering the number of data lying within the zone of tensional and hybrid fractures, it is evident that there has been an overall volumetric gain in the metabasalts, with the steady influx of fluid triggering the process of vein emplacement. This is also in accordance with the transtensional to pure strike-slip stress regime for which $R^{\prime}=2-\mathrm{R}$, where $R^{\prime}$ and $R$ are the stress regime index and stress ratio respectively. For transtensional to pure strike-slip stress regime, $R^{\prime}$ value ranges between 1 and 1.5 (Delvaux \& Sperner, 2003). In this study, $R^{\prime}=1.25$ suggests a transtensional to pure strike-slip stress regime under which the fractures and faults were reactivated, as evident from the palaeostress analysis (see section 4.5 in Bhowmick \& Mondal, 2020)).

The faults and fractures of the metabasalts of Chitradurga region are investigated to analyse their reactivation potential and failure modes. The brittle structures being related to the regional D3 deformation (late phase) suffered fluid-induced reactivation under multiple $P_{\mathrm{f}}$ cycles in the presence of the tectonic stress field (WNW-ESE-directed compression related to late D3 deformation). The variation of parameters like slip tendency, dilation tendency and fracture susceptibility with fracture orientation and stress ratios have been graphically examined. Fracture orientations parallel to the pre-existing metabasalt fabric (WSW and NE clusters) hosting quartz veins of maximum thickness give higher values for both slip/dilation tendencies. Among these, the steeply dipping fractures $\left(\sim 75-90^{\circ}\right)$ underwent tensional failure (high dilation tendency; Fig. 11), while shear failure is evident in the moderately dipping ones ( $\sim 45-60^{\circ}$; high slip tendency). $\mathrm{T}$ fractures are dominantly tensile from field evidences. The rest of the fractures resembling $\mathrm{X}$ and $\mathrm{R}^{\prime}$ components (SE cluster) along with some of the R, Y, P fractures range between tensile and shear modes, with hybrid mode forming a transition between both.

\section{Conclusions}

Reactivation potential of fractures can be successfully evaluated from parameters like slip tendency, dilation tendency, fracture susceptibility and opening angle, where field data are inadequate to determine the failure modes in fractures. Variation in failure mode along fracture surfaces is controlled by the dip of the fracture plane in spite of having similar orientations with respect to the far-field compression (tectonic stress). Obtaining slip versus dilation tendency and opening angle versus fracture orientation patterns are extremely useful for understanding the reactivation potential, deformation behaviour and failure modes in fracture networks that otherwise lack direct field evidence, especially if such reactivations 


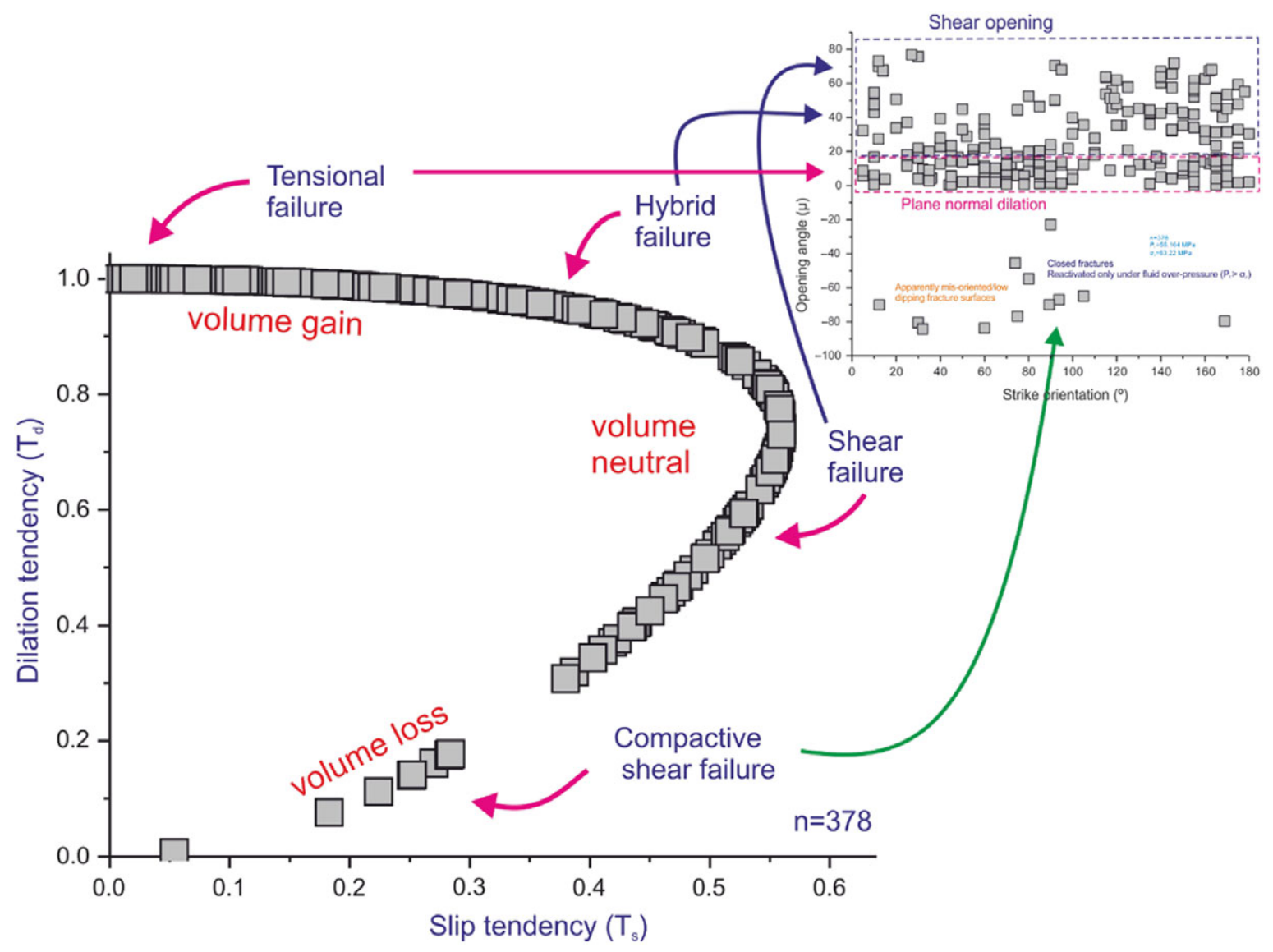

Fig. 10. General graphical relation between slip tendency and dilation tendency (after Ferrill et al. 2019a) defining the mode of failure in the fractures and faults of the study area. Range of opening angles specified for each mode of failure indicating an overall volumetric gain due to vein emplacement.

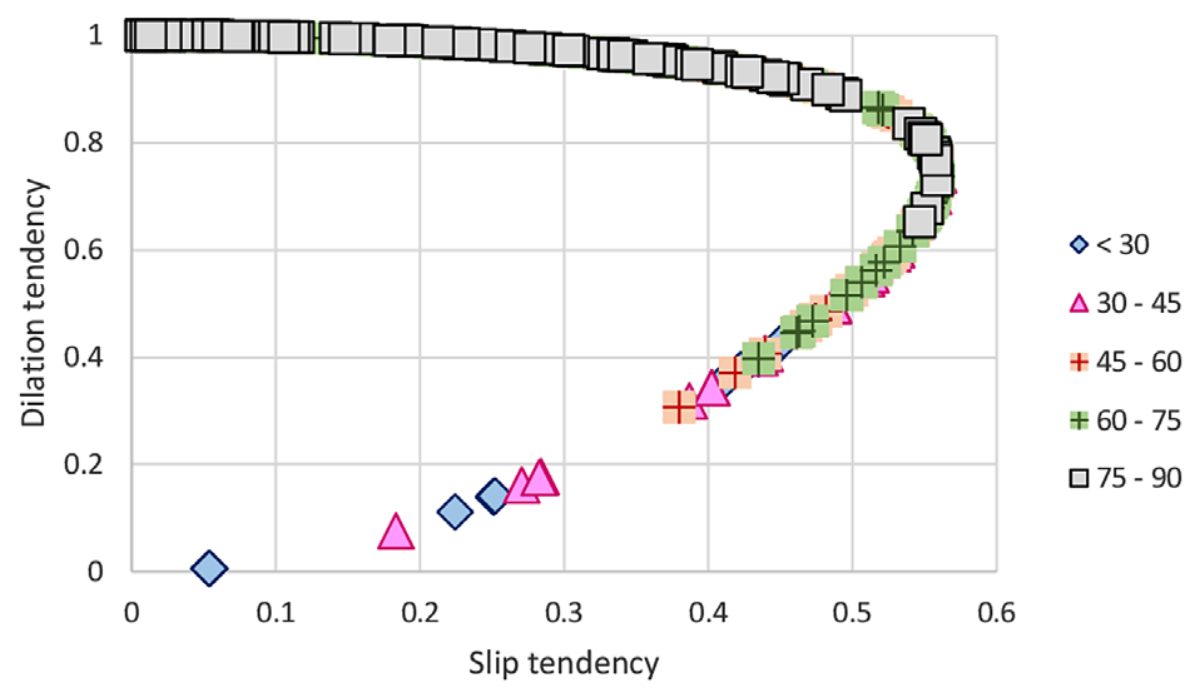

Fig. 11. Slip versus dilation tendency pattern showing dependence of these parameters on the dip of the fracture plane. The coloured symbols represent the dip $\left({ }^{\circ}\right)$ ranges of the fractures. Dips of $<30^{\circ}$ and $30-45^{\circ}$ (fracture plane dip) are consistent with compactive failure and compactive shear failure with negative opening angles (very low dilation tendency). Dip of $45-60^{\circ}$ stands for shear failure (high slip tendency). Dip of $60-75^{\circ}$ stands for hybrid failure (moderate slip and dilation tendency); medium to high opening angles. Dip of $75-90^{\circ}$ consistent with tensional fractures (high dilation tendency), low opening angles. 
are fluid-induced and multiple fluid pressure changes make it difficult to segregate the individual cycles.

Acknowledgements. This study is an extended part of SB's doctoral research, being funded by DST Inspire (IF170912). The study is mostly funded by the Indian Statistical Institute research grant, and partly funded by DST-SERB (file no. ECR/2015/000079) and RUSA 2.0 to TKM. The Geological Survey of India (Bangalore) is acknowledged for helping with logistic support and discussions during fieldwork. We personally thank Dr Thirukumaran Venugopal. Discussions with Dr Kevin J Smart were immensely useful. Detailed reviews by Prof. Francesco Mazzarini and an anonymous reviewer helped to improve the paper considerably. Editorial handling by Prof. Stefano Tavani and Prof Olivier Lacombe is greatly appreciated. Assistance provided by Ayan Patsa, Subha Saha and Swarnasree Mondal is acknowledged. SB also acknowledges the wholehearted support and blessings of Sunil Kumar Bhowmick, Gouri Bhowmick, Ranendranath Chakraborty and Chanchal Pandey.

\section{Conflicts of interest. None.}

Supplementary material. To view supplementary material for this article, please visit https://doi.org/10.1017/S0016756821000881

\section{References}

Angelier, J and Colletta, B (1983) Tension fractures and extensional tectonics. Nature 301, 49-51.

Attewell, PB and Sandford, MR (1974) Intrinsic shear strength of a brittle, anisotropic rock - I. Experimental and mechanical interpretation. International Journal of Rock Mechanics and Mining Sciences of Geomechanics Abstracts 11, 423-30.

Baer, G, Beyth, M and Reches, Z (1994) Dikes emplaced into fractured basement, Timna Igneous Complex, Israel. Journal of Geophysical Research 99, 24039-51. https://doi.org/10.1029/94JB02161.

Bhowmick, $\mathbf{S}$ and Mondal, TK (2020) Control of pre-existing fabric in fracture formation, reactivation and vein emplacement under variable fluid pressure conditions: an example from Archean Greenstone belt, India. Solid Earth 11, 1227-46. doi: 10.5194/se-11-1227-2020.

Chadwick, B, Ramakrishnan, M, Vasudev, VN and Viswanatha, MN (1989) Facies distributions and structure of a Dharwar volcano sedimentary basin: evidence for late Archaean transpression in Southern India? Journal of the Geological Society of London 146, 825-34.

Chadwick, B, Vasudev, VN and Hedge, GV (2003) The Chitradurga schist belt and its adjacent plutonic rocks NW of Tungabhadra, Karnataka: a duplex in the late Archean convergent setting of the Dharwar craton. Journal of the Geological Society of India 61, 611-13.

Chakrabarti, C, Mallick, BS, Pyne, TK and Guha, D (2006) A Manual of the Geology of India. Kolkata: Geological Survey of India.

Curzi, M, Aldega, L, Bernasconi, SM, Berra, F, Billi, A, Boschi, C, Franchini, S, Van der Lelij, R, Viola, G and Carminati, E (2020) Architecture and evolution of an extensionally-inverted thrust (Mt. Tancia Thrust, Central Apennines): geological, structural, geochemical, and $\mathrm{K}-\mathrm{Ar}$ geochronological constraints. Journal of Structural Geology, 136, 104059.

Delaney, PT, Pollard, DD, Zioney, JI and McKee, EH (1986) Field relations between dikes and joints: emplacement processes and palaeostress analysis. Journal of Geophysical Research 91, 4920-38. doi: 10.1029/JB091iB05p04920.

Delvaux, D and Sperner, B (2003) Stress tensor inversion from fault kinematic indicators and focal mechanism data: the TENSOR program. In New Insights into Structural Interpretation and Modelling (ed. D. Nieuwland), pp. 75-100. Geological Society of London, Special Publication no. 212.

Donath, FA (1961) Experimental study of shear failure in anisotropic rocks. Geological Society of America Bulletin 72, 985-90.

Ferrill, DA, Evans, MA, McGinnis, RN, Morris, AP, Smart, KJ, Wigginton, SS, Gulliver, KDH, Lehrmann, D, de Zoeten, E and Sickmann, Z (2017a) Fault zone processes in mechanically layered mudrock and chalk. Journal of Structural Geology 97, 118-43.

Ferrill, DA, Morris, AP and McGinnis, RN (2019b) Geologic structure of the Edwards (Balcones Fault Zone) Aquifer. In The Edwards Aquifer: The Past, Present, and Future of a Vital Water Resource (eds JM Sharp, RT Green and
GM Schindel), pp. 171-88. Geological Society of America Memoir 215,. doi: 10.1130/2019.1215(14).

Ferrill, DA, Smart, KJ and Morris, AP (2019a) Fault failure modes, deformation mechanisms, dilation tendency, slip tendency, and conduits v. seals. In Integrated Fault Seal Analysis (eds SR Ogilvie, SJ Dee, RW Wilson and WR Bailey). Geological Society of London, Special Publication no. 496, 75-98. doi: 10.1144/SP496-2019-7.

Ferrill, DA, Smart, KJ and Morris, AP (2020) Resolved stress analysis, failure mode, and fault-controlled fluid conduits in low-permeability strata. Solid Earth 11, 899-908. doi: 10.5194/se-2020-17.

Ferrill, DA, Winterle, J, Wittmeyer, G, Sims, D, Colton, S, Armstrong, A and Morris, AP (1999) Stressed rock strains groundwater at Yucca Mountain, Nevada. GSA Today $9,1-8$

Hancock, PL (1985) Brittle microtectonics: principles and practice. Journal of Structural Geology 7, 437-57.

Hancock, PL and Engelder, T (1989) Neotectonic joints. Geological Society of America Bulletin 101, 1197-208.

Healy, D (2017) FracTend MATLAB code, GitHub. https:/github.com/ DaveHealy-Aberdeen/FracTend (last accessed February 2020).

Hoek, E (1964) Fracture of anisotropic rock. Journal of the South African Institute of Mining and Metallurgy 64, 501-18.

Ikari, MJ, Neimeijer, AR and Marone, C (2015) Experimental investigation of incipient shear failure in foliated rock. Journal of Structural Geology 77, 8291. doi: 10.1016/j.jsg.2015.05.012.

Jayananda, M, Chardon, D, Peucat, J-J and Capdevila, R (2006) $2.61 \mathrm{Ga}$ potassic granites and crustal reworking in the western Dharwar craton, southern India: tectonic, geochronologic and geochemical constraints. Precambrian Research 150, 1-26. doi: 10.1016/j.precamres.2006.05.004.

Jayananda, M, Peucat, J-J, Chardon, D, Krishna Rao, B, Fanning, MC and Corfu, F (2013) Neoarchean greenstone volcanism and continental growth, Dharwar craton, south India: constraints from SIMS U-Pb zircon geochronology and Nd isotopes. Precambrian Research 227, 55-76.

Jolly, RJH and Sanderson, DJ (1997) A Mohr circle reconstruction for the opening of a pre-existing fracture. Journal of Structural Geology 19, 88792. doi: 10.1016/S0191-8141(97)00014-X.

Mazzarini, F, Musumeci, G, Viola, G, Garofalo, PS and Mattila, J (2019) Structural and lithological control on fluid circulation, dilation and ore mineralization (Rio Albano mine, Island of Elba, Italy). Journal of Structural Geology 126, 210-30. doi: 10.1016/j.jsg.2019.06.012.

McGarr, A (1980) Some constraints on levels of shear stress in the crust from observations and theory. Journal of Geophysical Research 85, 6231-8. doi: 10. 1029/JB085iB11p06231.

Mildren, SD, Hillis, RR and Kaldi, J (2002) Calibrating predictions of fault seal reactivation in the Timor Sea. The APPEA Journal 42, 187-202.

Miller, LD, Goldfarb, RJ, Gehrels, GE and Snee, LW (1994) Genetic links among fluid cycling, vein formation, regional deformation, and plutonism in the Juneau goldbelt, southeastern Alaska. Geology 22, 203-6.

Mondal, TK (2018) Evolution of fabric in Chitradurga granite (south India): a study based on microstructure, anisotropy of magnetic susceptibility (AMS) and vorticity analysis. Tectonophysics 723, 149-61. doi: 10.1016/j.tecto.2017. 12.013 .

Mondal, TK and Acharyya, SS (2018) Fractured micro-granitoid enclaves: a stress marker. Journal of Structural Geology 113, 33-41. doi: 10.1016/j.jsg 2018.05.011

Mondal, TK, Bhowmick, S, Das, S and Patsa, A (2020) Paleostress field reconstruction in the western Dharwar Craton, south India: evidences from brittle faults and associated structures of younger granites. Journal of Structural Geology 135, 104040. doi: 10.1016/j.jsg.2020.104040.

Mondal, TK and Mamtani, MA (2013) 3-D Mohr circle construction using vein orientation data from Gadag (southern India): implications to recognize fluid pressure fluctuation. Journal of Structural Geology 56, 45-56. doi: 10. 1016/j.jsg.2013.08.005.

Mondal, TK and Mamtani, MA (2014) Fabric analysis in rocks of the Gadag region (southern India): implications for time relationship between regional deformation and gold mineralization. Tectonophysics 629, 238-49. doi: 10. 1016/j.tecto.2013.09.021

Mondal, TK and Mamtani, MA (2016) Palaeostress analysis of normal faults in granite: implications for interpreting Riedel shearing related to regional 
deformation. Journal of the Geological Society 173, 216-27. doi: 10.1144/ jgs2014-136.

Morris, A, Ferrill, DA and Henderson, DB (1996) Slip-tendency analysis and fault reactivation. Geology 24, 275-8.

Naqvi, SM and Rogers, JJW (1987) Precambrian Geology of India. Oxford Monographs on Geology and Geophysics no. 6. New York: Oxford University Press.

Ramsay, JG and Huber, MI (1983) The Techniques of Modern Structural Geology, vol. 1: Strain Analysis. London: Academic Press.

Rowan, MG, Muñoz, JA, Giles, KA, Roca, E, Hearon IV, TE, Fiduk, JC, Ferrer, $\mathbf{O}$ and Fischer, MP (2020) Folding and fracturing of rocks adjacent to salt diapirs. Journal of Structural Geology 141, 104187.

Sarma, DS, Fletcher, IR, Rasmussen, B, McNaughton, NJ, Mohan, MR and Groves, DI (2011) Archean gold mineralization synchronous with late cratonization of the Western Dharwar Craton, India: $2.52 \mathrm{Ga} \mathrm{U}-\mathrm{Pb}$ ages of hydrothermal monazite and xenotime in gold deposits. Mineralium Deposita 46, 273-88. doi: 10.1007/s00126-010-0326-3.

Sibson, RH (1992) Implications of fault-valve behaviour for rupture nucleation and recurrence. Tectonophysics 211, 283-93. doi: 10.1016/0040-1951(92)90065-E.

Sibson, RH (1996) Structural permeability of fluid-driven fault-fracture meshes. Journal of Structural Geology 18, 1031-43. doi: 10.1016/01918141(96)00032-6.

Sibson, RH (2000) A brittle failure mode plot defining conditions for high fluxflow. Economic Geology 95, 41-8. doi: 10.2113/gsecongeo.95.1.41.
Stephens, TL, Walker, RJ, Healy, D, Bubeck, A and England, RW (2018) Mechanical models to estimate the paleostress state from igneous intrusions. Solid Earth 9, 847-58. doi: 10.5194/se-9-847-2018.

Stephens, TL, Walker, RJ, Healy, D, Bubeck, A, England, RW and McCaffrey, KJ (2017) Igneous sills record far-field and near-field stress interactions during volcano construction: Isle of Mull, Scotland. Earth and Planetary Science Letters 478, 159-74. doi: 10.1016/j.epsl.2017.09. 003.

Tavani, S, Storti, F, Lacombe, O, Corradetti, A, Muñoz, JA and Mazzoli, S (2015) A review of deformation pattern templates in foreland basin systems and fold-and-thrust belts: implications for the state of stress in the frontal regions of thrust wedges. Earth-Science Reviews 141, 82-104.

Thyng, KM, Greene, CA, Hetland, RD, Zimmerle, HM and DiMarco, SF (2016) True Colors of Oceanography Guidelines for Effective and Accurate Colormap Selection. Oceanography 29, 9-13.

Vishnu, CS, Lahiri, S and Mamtani, MA (2018) The relationship between magnetic anisotropy, rock-strength anisotropy and vein emplacement in gold-bearing metabasalts of Gadag (South India). Tectonophy $\mathbf{7 2 2}$ 286-98.

Yamaji, A and Sato, K (2011) Clustering of fracture orientations using a mixed Bingham distribution and its application to paleostress analysis from dike or vein orientations. Journal of Structural Geology 33, 1148 57. doi: 10.1016/j.jsg.2011.05.006. 